\title{
IMPLEMENTASI ALGORITMA C5.0 UNTUK MENENTUKAN PELANGGAN POTENSIAL DI KANTOR POS CIMAHI
}

\author{
Nisa Hanum Harani ${ }^{1}$, Fanny Shafira Damayanti ${ }^{2}$ \\ ${ }_{1,2}$ Politeknik Pos Indonesia
}

Article Info:

Dikirim: 21 Juni 2021

Direvisi: 27 Juni 2021

Diterima: 29 Juni 2021

Tersedia Online: 30 Juni 2021

Penulis Korespondensi:

Nisa Hanum Harani

Politeknik Pos Indonesia,

Bandung, Indonesia

Email: nisahanum@poltekpos.ac.id

\begin{abstract}
Abstrak: Saat ini banyak perusahaan swasta yang bergerak di bidang jasa pengiriman yang mengakibatkan banyaknya pesaing bagi Kantor Pos Cimahi dan dapat mengakibatkan penurunan jumlah pelanggan yang menggunakan jasa Kantor Pos Cimahi. Oleh karena itu, diperlukan suatu sistem untuk membantu Kantor Pos Cimahi dalam mengidentifikasi calon pelanggan, sehingga dapat diketahui calon pelanggan mana yang dapat memperoleh perlakuan khusus, sehingga pelanggan tersebut dapat terus menggunakan jasa Kantor Pos Cimahi. Sistem yang dibangun menggunakan bahasa pemrograman PHP dan metode Algoritma C 5.0 yang merupakan salah satu algoritma pohon keputusan yang dapat membantu untuk menentukan pelanggan potensial. Penelitian menggunakan data transaksi periode bulan januari - oktober 2020 dimana atribut yang digunakan yaitu bulan, nama perusahaan, jenis kiriman yang digunakan, jumlah transaksi selama sebulan, dan total uang. Hasil penelitian menunjukan bahwa algoritma C 5.0 mampu melakukan menentukan data pelanggan potensial dengan akurasi sebesar $96 \%$.
\end{abstract}

Kata kunci: kantor pos cimahi; pohon keputusan; PHP; algoritma C 5.0.

\begin{abstract}
Currently, there are many private companies engaged in shipping services which have resulted in many competitors for the Cimahi Post Office and may result in a decrease in the number of customers who use the services of the Cimahi Post Office. Therefore, a system is needed to assist the Cimahi Post Office in identifying potential customers, so that it can be seen which prospective customers can receive special treatment, so that these customers can continue to use the services of the Cimahi Post Office. The system built using the PHP programming language and the C 5.0 Algorithm method, which is a decision tree algorithm that can help determine potential customers. The study used transaction data for the period January - October 2020 where the attributes used were month, company name, type of shipment used, number of transactions for a month, and total money. The results showed that the $C 5.0$ algorithm was able to determine potential customer data with an accuracy of $96 \%$.
\end{abstract}

Keywords: cimahi post office; decision tree; PHP; C 5.0 algortithm. 


\section{PENDAHULUAN}

Kantor Pos Cimahi merupakan cabang dari Pt. Pos Indonesia, serta merupakan perusahaan milik negara yang bergerak di bidang pengiriman barang. Kantor Pos Cimahi memiliki mitra-mitra atau perusahaanperusahaan yang tergabung untuk melakukan pengiriman surat dan paket. Mitra-mitra yang bekerjasama dengan Kantor Pos Cimahi itu disebut sebagai pelanggan korporat. Pelanggan korporat menggunakan jasa dari Kantor Pos Cimahi untuk mengirimkan barang atau surat mereka [1].

Sebagai perusahaan yang bergerak dalam bidang jasa pengiriman barang, Kantor Pos Cimahi memiliki banyak pesaing dalam bidang yang sama sehingga akan memberikan ancaman bagi perusahaan untuk kehilangan pelanggannya. Dikarenakan banyaknya pesaing, Kantor Pos Cimahi harus memiliki strategi dalam pengelolaan pelanggan agar pelanggan tidak jatuh ke tangan pesaing.

Pesatnya perkembangan teknologi mengakibatkan dunia ini dipenuhi dengan data [2]. Pada tahun 2020 dari bulan januari hingga oktober transaksi pelanggan korporat sebanyak 150000 transaksi. Dari banyaknya data transaksi tersebut berdampak pada sulitnya dalam mengklasifikasi pelanggan pada sebuah perusahaan. Dengan banyaknya data transaksi itu tidak mungkin untuk diolah secara manual oleh karena itu dibutuhkan sebuah teknologi untuk dapat mengolahnya [3].

Sebuah data memiliki informasi didalamnya, namun kebanyakan perusahaan tidak dapat memanfaatkan informasi dari data yang mereka miliki. Apabila data yang dimiliki oleh perusahaan diolah dengan benar maka perusahaan akan mendapatkan informasi yang berharga yang akan berguna dikemudian hari. Teknik yang dapat mengelola data menjadi sebuah informasi yang berguna adalah menggunakan Teknik data mining dengan Teknik clustering atau pengelompokkan [4].

Berdasarkan masalah yang dijelaskan sebelumnya, penelitian ini akan merancang sebuah sistem untuk mengolah data penjualan korporat di Kantor Pos Cimahi menggunakan metode algoritma C 5.0. Algoritma C 5.0 digunakan untuk mengetahui nilai information gain paling tinggi untuk menentukan akar terbaik yang akan dijadikan node atau cabang [5]. Sistem ini dibuat untuk dapat mengetahui pelanggan mana yang potensial dan yang mana yang tidak potensial sehingga dengan mengetahui apakah pelanggan itu merupakan pelanggan potensial akan diberikan treatment khusus misalkan berupa pemetongan harga ongkos kirim barang yang pada akhirnya pelanggan tersebut akan tetap menggunakan jasa pengiriman Kantor Pos Cimahi.

Dalam penelitian ini penulis menggunakan atribut bulan, nama perusahaan, jenis produk, jumlah transaksi dan total uang sebagai atribut yang akan di analisis menggunakan algoritma C 5.0. Dengan algoritma C 5.0 diharapkan dapat menghasilkan analisis yang akurasinya tinggi dan keputusan yang tepat berdasarkan atributatribut yang telah dianalisis untuk menentukan pelanggan potensial [6].

\section{METODOLOGI PENELITIAN}

\subsection{Waterfall}

Model Waterfall digunakan peneliti untuk melakukan pengembangan pernagkan lunak secara sekuensial dan bertahap [7]. Gambar 1 di bawah ini merupakan diagram alur waterfall.

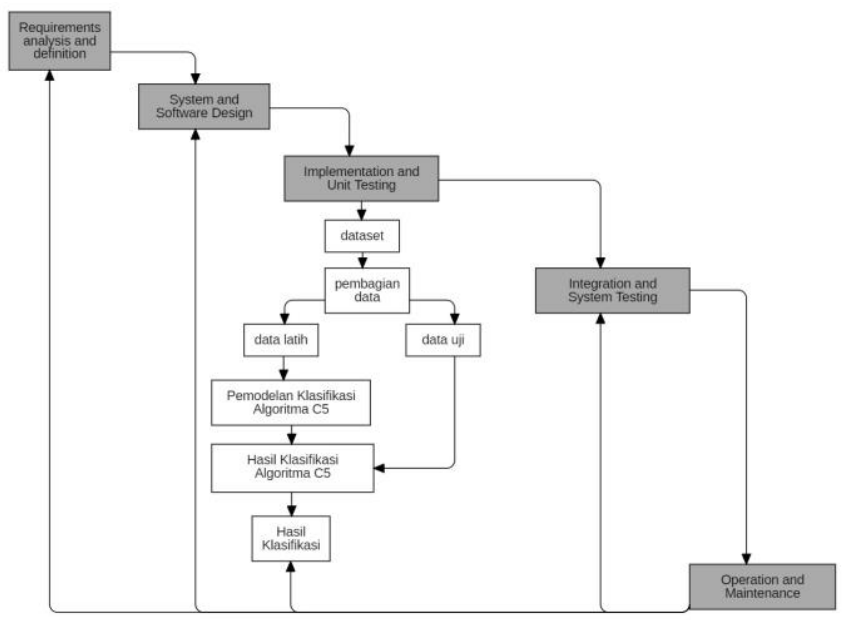

Gambar 1. Diagram Alur Metodologi Penelitian

Metode Waterfall memiliki tahapan-tahapan sebagai berikut [8]:

a. Tahapan analisis 
Tahap ini merupakan tahap untuk memahami masalah dan menjabarkannya kemudian menentukan tujuan dari penelitian. Observasi dan wawancara dilakukan untuk mengetahui masalah yang ada dilapangan.

1) Observasi

Hasil dari observasinya adalah pada Kantor Pos Cimahi belum ada sistem khusus yang mengelola data-data penjualan pelanggan korporat sehingga menyulitkan bagian penjualan untuk mengelola data penjualan yang akan dijadikan laporan serta belum ada sistem yang memiliki fitur untuk menentukan pelanggan potensial. Fitur untuk menentukan pelanggan potensial berguna bagi Kantor Pos Cimahi khususnya bagian penjualan dalam mempertahankan pelanggan agar tetap menggunakan jasa Kantor Pos Cimahi.

2) Wawancara

Wawancara dengan pembimbing eksternal yang dilakukan penulis dilakukan pada

a) Tanggal : 19 Januari 2021

b) Tempat: Kantor Pos Cimahi

c) Jam : 13:00 WIB

d) Hasil : data yang diperoleh berupa proses penentuan pelanggan potensial di Kantor Pos Cimahi, serta kriteria apa saja yang menjadikan pelanggan itu sebagai pelanggan potensial.

b. Tahapan desain

Pada tahap ini peneliti akan men design sistem berdasarkan hasil dari tahap requirements analysis and definition.

c. Tahapan implementasi

Pada pembuatan sistem ini, peneliti menggunakan bahasa pemrograman PHP serta menggunakan metode algoritma C 5.0 untuk menentukan pelanggan potensial di Kantor Pos Cimahi. Langkah Langkah dalam mengimplementasikan algortima C 5.0 kedalam sistem adalah sebagai berikut :

1) Dataset

Dataset merupakan data transaksi penjualan SLPK pada bulan januari hingga oktober 2020. Dalam penelitian ini penulis menggunakan atribut bulan, nama perusahaan, jenis produk, jumlah transaksi, total uang dan label. Variabel bebas diantaranya bulan, nama perusahaan, jenis produk, jumlah transaksi, total uang, sedangkan variabel terikat yaitu label potensial dan tidak. Data tersebut akan di klasifikasi menggunakan algoritma C 5.0. Dataset yang digunakan pada penelitian ini dapat dilihat pada Gambar 2 .

\begin{tabular}{|c|c|c|c|c|}
\hline id_datase $\square$ bulan & - nama_perusahaan & - jenis_kiriman & - jumlah_transaks & total_uang \\
\hline 1 januari & BPJS KESEHATAN & SKH & 37 & 263000 tidak \\
\hline 2 januari & BLBI ABIYOSO & PPKH & 873 & 108402501 potensial \\
\hline 3 januari & BPKP JABAR & SKH & 266 & 3201001 potensial \\
\hline 4 januari & RSUD CIBABAT & EXP CORPORATE & 5 & 95500 tidak \\
\hline 5 januari & PT ALFA OMEGA INDUSTRI & EXP CORPORATE & 2 & 3131000 tidak \\
\hline 6 januari & BPJS KETENAGAKERJAAN & SKH & 1809 & 13224500 potensial \\
\hline 7 januari & KPP PRATAMA SOREANG & SKH & 490 & 5064500 potensial \\
\hline 8 januari & KPP PRATAMA CIMAHI & SKH & 7168 & 51412301 potensial \\
\hline 9 januari & ULTRAJAYA MILK INDUSTRY & SKH & 846 & 31064000 potensial \\
\hline 10 januari & BALAI DIKLAT KEUANGAN & EXP CORPORATE & 13 & 180500 tidak \\
\hline 11 januari & SINAR CONTINENTAL & EXP CORPORATE & 191 & 6272603 tidak \\
\hline 12 januari & FAMILY ONLINE SHOP & EXP CORPORATE & 80 & 9253600 potensial \\
\hline 13 januari & ATEJA TRITUNGGAL CORPORATION & V LOGISTIK & 356 & 410969000 potensial \\
\hline 14 januari & DINAS PERIJINAN BANDUNG BARAT & T EXP CORPORATE & 107 & 1107500 potensial \\
\hline 15 januari & WOM FINANCE & SKH & 340 & 2145000 potensial \\
\hline 16 januari & ADIRA DINAMIKA FINANCE & SKH & 13 & 1164100 tidak \\
\hline 17 januari & MEGA FINANCE & SKH & 559 & 4057000 potensial \\
\hline 18 januari & BJB & SKH & 20 & 373500 tidak \\
\hline 19 januari & BPJS KESEHATAN & SKH & 37 & 263000 tidak \\
\hline 20 januari & BLBI ABIYOSO & PPKH & 873 & 108402501 potensial \\
\hline
\end{tabular}

\section{Gambar 2. Dataset}

2) Pembagian data

Data latih dibagi sebanyak $70 \%$ dan data uji dibagi sebanyak 30\% dari total keseluruhan data.

3) Pemodelan Klasifikasi Algoritma C 5.0

Pada tahap ini dilakukan klasifikasi data berdasarkan metode Algortima C 5.0 yang hasilnya akan membentuk sebuah data baru.

4) Hasil Klasifikasi Algoritma C 5.0

Selanjutnya adalah hasil klasifikasi algoritma C 5.0 Hasil klasifikasi nantinya akan dibandingkan kelas yang sebenarnya.

5) Hasil Klasifikasi

Hasil klasifikasi akan dianalisa kembali untuk mengetahui apakah dapat digunakan untuk proses klasifikasi pada penentuan pelanggan potensial di Kantor Pos Cimahi. 
d. Tahapan pengujian

Tahap ini yaitu mengintegrasikan sistem dan sistem akan diuji apakah sistem tersebut berfungsi dengan baik.

e. Tahapan operasi

Pada tahap ini sistem yang telah jadi digunakan oleh client dan dilakukan pemeliharaan.

\subsection{Algoritma C 5.0.}

Algoritma C 5.0 merupakan metode yang digunakan penulis untuk menentukan pelanggan potensial di Kantor Pos Cimahi. Dalam proses pembentukan pohon keputusan nilai informasi gain tertinggi akan terpilih sebagai root bagi node selanjutnya. Rumus (1) merupakan rumus untuk mengetahui entropy keseluruhan dan entropy setiap atribut [9] :

$$
\operatorname{Entropy}(S)=\sum_{i=1}^{n}-p i * \log _{2} p i
$$

Dimana S merupakan jumlah dari kasus, n merupakan jumlah dari partisi $\mathrm{S}$ dan pi merupakan rasio $\mathrm{Si}$ terhadap $\mathrm{S}$.

Rumus (2) merupakan rumus untuk mengetahui gain dari setiap atribut :

$$
\operatorname{Gain}(S, A)=\operatorname{Entropy}(S)-\sum_{i=1}^{n} \frac{|S i|}{|S|} * \text { Entropy }(S i)
$$

Dimana S merupakan jumlah kasus, A merupakan atribut yang digunakan, n merupakan jumlah partisi atribut, $|\mathrm{Si}|$ merupakan jumlah kasus pada partisi ke-I dan $|\mathrm{S}|$ merupakan jumlah kasus yang ada di S.

Rumus (3) merupakan rumus untuk menghitung gain ratio :

$$
\text { Gain Ratio }=\frac{\operatorname{Gain}(S, A)}{\sum_{i=1}^{n} \operatorname{Entropy}(S i)}
$$

Dimana Gain $(S, A)$ merupakan nilai gain dari variabel dan $\sum_{i=1}^{n}$ Entropy $(S i)$ merupakan banyaknya nilai entropy dalam suatu variable

\section{HASIL DAN PEMBAHASAN}

\subsection{Klasifikasi Decision Tree Algoritma C 5.0}

Tahap awal yang harus dilakukam adalah memilih node dengan menggunakan rumus (1), rumus (2) dan rumus (3).

a. Perhitungan entropy tiap variabel dan entropy total menggunakan rumus (1), diperoleh entropy total adalah sebesar 0,999717128.

b. Perhitungan gain menggunakan rumus (2).

c. Perhitungan gain ratio menggunakan rumus (3), diperoleh gain ratio terbesar yaitu Jumlah Transaksi sebesar 0,828709376.

Tabel 1. Node 1

\begin{tabular}{llcccccc}
\hline & & $\begin{array}{c}\text { Jumlah } \\
(\text { S })\end{array}$ & $\begin{array}{c}\text { Potensial } \\
(\text { Si })\end{array}$ & $\begin{array}{c}\text { Tidak } \\
(\text { Si })\end{array}$ & Entropy & Gain & Gain Ratio \\
\hline Total & & 404 & 198 & 206 & 0,999717128 & & \\
Bulan & & & & & & 1,801575265 & 0,185149705 \\
& Januari & 36 & 22 & 14 & 0,964078765 & & \\
& Februari & 38 & 22 & 16 & 0,981940787 & & \\
& Maret & 38 & 26 & 12 & 0,899743759 & & \\
& April & 40 & 20 & 20 & 1 & & \\
& Mei & 42 & 18 & 24 & 0,985228136 & & \\
& Juni & 42 & 20 & 22 & 0,998363673 & & \\
& Juli & 42 & 16 & 26 & 0,958711883 & & \\
& Agustus & 42 & 18 & 24 & 0,985228136 & & \\
& September & 42 & 20 & 22 & 0,998363673 & &
\end{tabular}

Perusahaan 
Jurnal SITECH, Vol 4, No 1, Juni 2021

P-ISSN : 2615-8531, E-ISSN : 2622-2973

\begin{tabular}{|c|c|c|c|c|c|c|c|}
\hline & & $\begin{array}{l}\text { Jumlah } \\
(S)\end{array}$ & $\begin{array}{l}\text { Potensial } \\
\text { (Si) }\end{array}$ & $\begin{array}{c}\text { Tidak } \\
(\mathrm{Si})\end{array}$ & Entropy & Gain & Gain Ratio \\
\hline \multirow{46}{*}{$\begin{array}{l}\text { Total } \\
\text { Bulan }\end{array}$} & & 404 & 198 & 206 & 0,999717128 & & \\
\hline & & & & & & 1,801575265 & 0,185149705 \\
\hline & Januari & 36 & 22 & 14 & 0,964078765 & & \\
\hline & Februari & 38 & 22 & 16 & 0,981940787 & & \\
\hline & Maret & 38 & 26 & 12 & 0,899743759 & & \\
\hline & April & 40 & 20 & 20 & 1 & & \\
\hline & Mei & 42 & 18 & 24 & 0,985228136 & & \\
\hline & Juni & 42 & 20 & 22 & 0,998363673 & & \\
\hline & Juli & 42 & 16 & 26 & 0,958711883 & & \\
\hline & Agustus & 42 & 18 & 24 & 0,985228136 & & \\
\hline & BPJS KESEHATAN & 20 & 16 & 4 & 0,721928095 & & \\
\hline & BLBI ABIYOSO & 20 & 16 & 4 & 0,721928095 & & \\
\hline & BPKP JABAR & 20 & 16 & 4 & 0,721928095 & & \\
\hline & RSUD CIBABAT & 20 & 0 & 20 & 0 & & \\
\hline & PT ALFA OMEGA & & & & & & \\
\hline & INDUSTRI & 4 & 0 & 4 & 0 & & \\
\hline & BPJS & & & & & & \\
\hline & KETENAGAKERJAAN & 20 & 12 & 8 & 0,970950594 & & \\
\hline & KPP PRATAMA & & & & & & \\
\hline & SOREANG & 20 & 20 & 0 & 0 & & \\
\hline & KPP PRATAMA & & & & & & \\
\hline & CIMAHI & 20 & 20 & 0 & 0 & & \\
\hline & ULTRAJAYA MILK & & & & & & \\
\hline & INDUSTRY & 20 & 20 & 0 & 0 & & \\
\hline & BALAI DIKLAT & & & & & & \\
\hline & KEUANGAN & 20 & 20 & 0 & 0 & & \\
\hline & SINAR & & & & & & \\
\hline & CONTINENTAL & 20 & 12 & 8 & 0,970950594 & & \\
\hline & $\begin{array}{l}\text { FAMILY ONLINE } \\
\text { SHOP }\end{array}$ & 20 & 10 & 10 & 1 & & \\
\hline & ATEJA TRITUNGGAL & 20 & 20 & 0 & 0 & & \\
\hline & DINAS PERIJINAN & 6 & 2 & 4 & 0,918295834 & & \\
\hline & WOM FINANCE & 20 & 8 & 12 & 0,970950594 & & \\
\hline & ADIRA DINAMIKA & 20 & 0 & 20 & 0 & & \\
\hline & MEGA FINANCE & 10 & 7 & 3 & 0,881290899 & & \\
\hline & BJB & 14 & 14 & 0 & 0 & & \\
\hline & BUNDA JAYA & & & & & & \\
\hline & HERBAL & 2 & 2 & 0 & 0 & & \\
\hline & COD BUNDA JAYA & 16 & 6 & 10 & 0,954434003 & & \\
\hline & $\begin{array}{l}\text { SEVENTMM } \\
\text { PERIJINAN PEMKAB }\end{array}$ & 2 & 0 & 2 & 0 & & \\
\hline & BDG & 12 & 2 & 10 & 0,650022422 & & \\
\hline & PD ANANG & 12 & 0 & 12 & 0 & & \\
\hline & KELULUSAN 2020 & 4 & 3 & 1 & 0,811278124 & & \\
\hline & BPKAD & 10 & 1 & 9 & 0,468995594 & & \\
\hline & BAPENDA & 6 & 1 & 5 & 0,650022422 & & \\
\hline & $\begin{array}{l}\text { BPJS KIS PBI } \\
\text { PT ANUGRAH }\end{array}$ & 8 & 3 & 5 & 0,954434003 & & \\
\hline & DWIJAYA LOG & 16 & 2 & 14 & 0,543564443 & & \\
\hline \multirow[t]{5}{*}{$\begin{array}{l}\text { Jenis } \\
\text { Kiriman }\end{array}$} & & & & & & 0.86897436 & 0.242176036 \\
\hline & SKH & 220 & 124 & 96 & 0,988283611 & & \\
\hline & PPKH & 20 & 16 & 4 & 0,721928095 & & \\
\hline & EXP CORPORATE & 114 & 34 & 80 & 0,879135767 & & \\
\hline & LOGISTIK & 50 & 24 & 26 & 0,998845536 & & \\
\hline \multirow{4}{*}{$\begin{array}{l}\text { Jumlah } \\
\text { Transaksi }\end{array}$} & & & & & & & \\
\hline & & & & & & 1,024119359 & 0,828709376 \\
\hline & $<=101$ & 202 & 29 & 173 & 0,593497957 & & \\
\hline & $>101$ & 202 & 169 & 33 & 0,64230242 & & \\
\hline
\end{tabular}




\begin{tabular}{|c|c|c|c|c|c|c|c|}
\hline & & $\begin{array}{c}\text { Jumlah } \\
(S)\end{array}$ & $\begin{array}{c}\text { Potensial } \\
(\mathrm{Si})\end{array}$ & $\begin{array}{c}\text { Tidak } \\
(\mathrm{Si})\end{array}$ & Entropy & Gain & Gain Ratio \\
\hline \multirow{10}{*}{$\begin{array}{l}\text { Total } \\
\text { Bulan }\end{array}$} & & 404 & 198 & 206 & 0,999717128 & \multirow{10}{*}{1,801575265} & \multirow{10}{*}{0,185149705} \\
\hline & & & & & & & \\
\hline & Januari & 36 & 22 & 14 & 0,964078765 & & \\
\hline & Februari & 38 & 22 & 16 & 0,981940787 & & \\
\hline & Maret & 38 & 26 & 12 & 0,899743759 & & \\
\hline & April & 40 & 20 & 20 & 1 & & \\
\hline & Mei & 42 & 18 & 24 & 0,985228136 & & \\
\hline & Juni & 42 & 20 & 22 & 0,998363673 & & \\
\hline & Juli & 42 & 16 & 26 & 0,958711883 & & \\
\hline & Agustus & 42 & 18 & 24 & 0,985228136 & & \\
\hline \multirow[t]{3}{*}{ Total Uang } & & & & & & 1,023057086 & 0,797040627 \\
\hline & $<=1996300$ & 202 & 31 & 171 & 0,618444821 & & \\
\hline & $>1996300$ & 202 & 167 & 35 & 0,665124738 & & \\
\hline
\end{tabular}

Berdasarkan data hasil perhitungan node 1 pada tabel 1, bisa dilihat bahwa nilai gain ratio tertinggi yaitu Jumlah Transaksi, maka Jumlah Transaksi akan dijadikan akar pohon node 1.

Tabel 2. Node 1.1

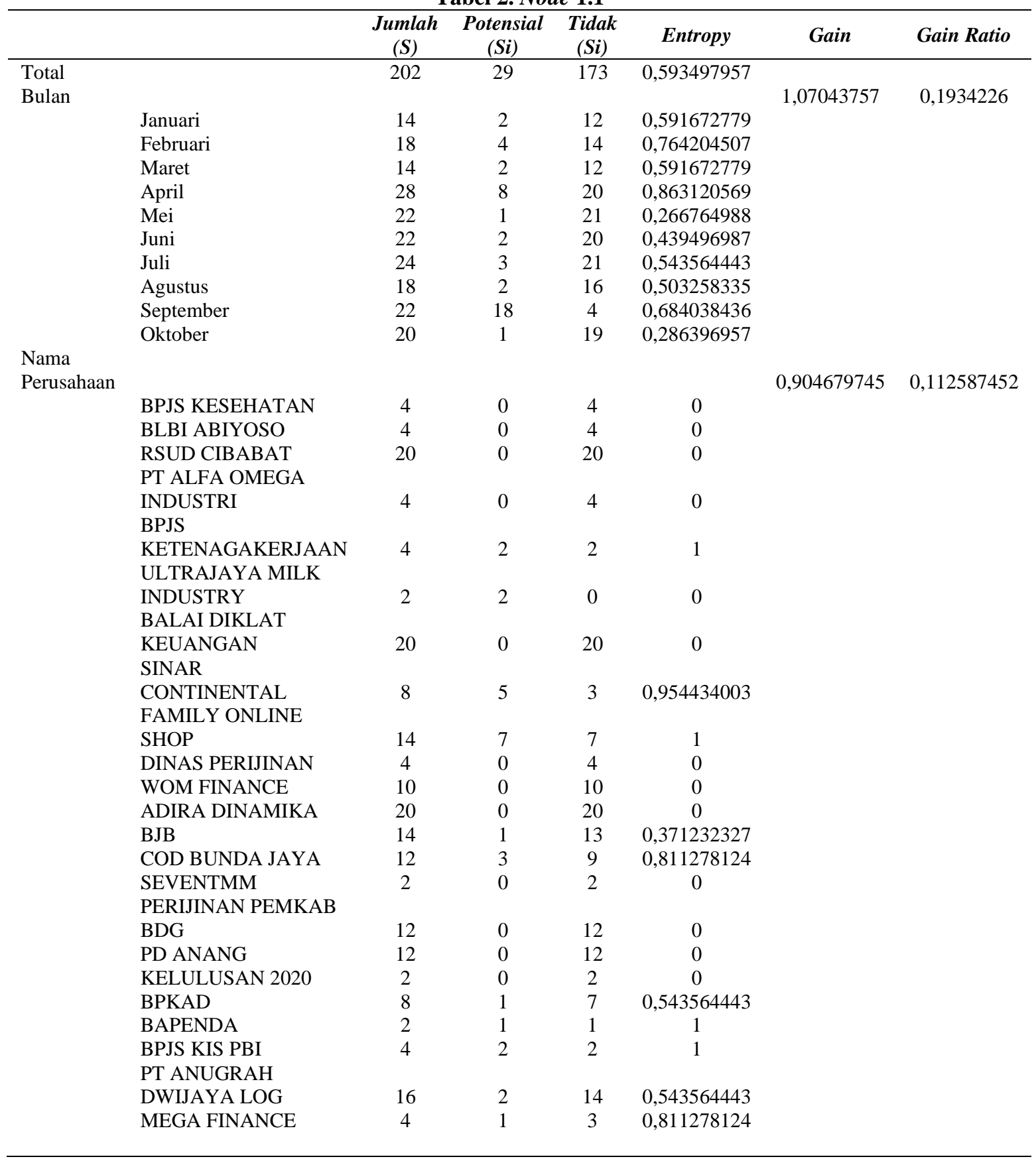


Jurnal SITECH, Vol 4, No 1, Juni 2021

$P-I S S N$ : 2615-8531, E-ISSN : 2622-2973

\begin{tabular}{|c|c|c|c|c|c|c|c|}
\hline & & $\begin{array}{c}\text { Jumlah } \\
(S)\end{array}$ & $\begin{array}{l}\text { Potensial } \\
\text { (Si) }\end{array}$ & $\begin{array}{c}\text { Tidak } \\
\text { (Si) }\end{array}$ & Entropy & Gain & Gain Ratio \\
\hline \multicolumn{8}{|l|}{ Jenis } \\
\hline \multirow[t]{5}{*}{ Kiriman } & & & & & & \multirow{5}{*}{0,731331545} & \multirow[t]{5}{*}{0,452808308} \\
\hline & SKH & 84 & 10 & 74 & 0,526617066 & & \\
\hline & PPKH & 4 & 0 & 4 & 0 & & \\
\hline & EXP CORPORATE & 86 & 17 & 69 & 0,717252478 & & \\
\hline & LOGISTIK & 28 & 2 & 26 & 0,371232327 & & \\
\hline \multirow[t]{3}{*}{ Total Uang } & & & & & & \multirow[t]{3}{*}{0,73198037} & \multirow[t]{3}{*}{0,631375022} \\
\hline & $<=183700$ & 114 & 8 & 106 & 0,366578013 & & \\
\hline & $>183700$ & 88 & 21 & 67 & 0,792765236 & & \\
\hline
\end{tabular}

Pada Tabel 2 terlihat bahwa gain ratio tertinggi adalah Total Uang, maka Total Uang akan menjadi root atau akar pohon dari node 1.1 .

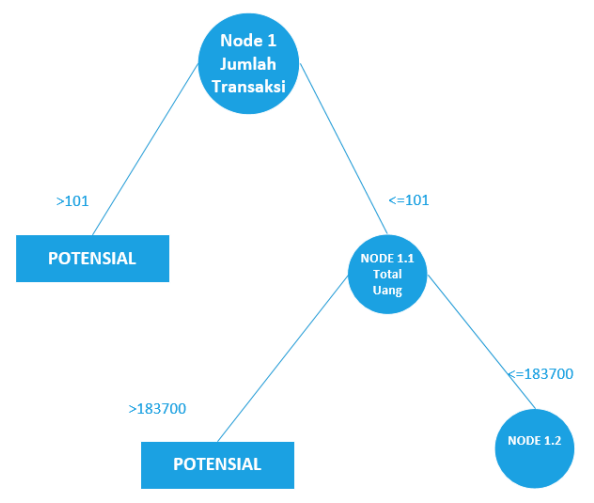

Gambar 3. Pohon Keputusan

Pada Gambar 3. bisa dilihat bahwa jika perusahaan yang jumlah transaksinya $>101$ maka perusahaan itu adalah potensial, jika perusahaan yang jumlah transaksinya $<=101$ dan total uangnya $>183700$ maka perusahaan tersebut potensial, dan jika perusahaan yang jumlah transaksinya $<=101$ dan total uang yang dihasilkannya itu $<=183700$ maka keputusannya belum ada karena harus dihitung lagi node atau akar 1.2.

Dari pohon keputusan yang terbentuk sesuai dengan algoritma C 5.0 yang dapat dilihat pada Gambar 3 diperoleh aturan sebagai berikut::

a. R1 = IF Jumlah Transaksi $>101$ THEN keputusan Potensial.

b. R2 = IF Jumlah Transaksi <=101 Total Uang >183700 THEN keputusan Potensial.

c. $\mathrm{R} 3=$ IF Total Uang $>183700$ THEN keputusan Potensial.

d. R4 = IF Total Uang <=183700 THEN keputusan belum diketahui.

\subsection{User Interface System}

a. Halaman Pohon Keputusan

Gambar 4 merupakan halaman berisi hasil pohon keputusan yang telah di hitung oleh sistem menggunakan Algoritma C 5.0.

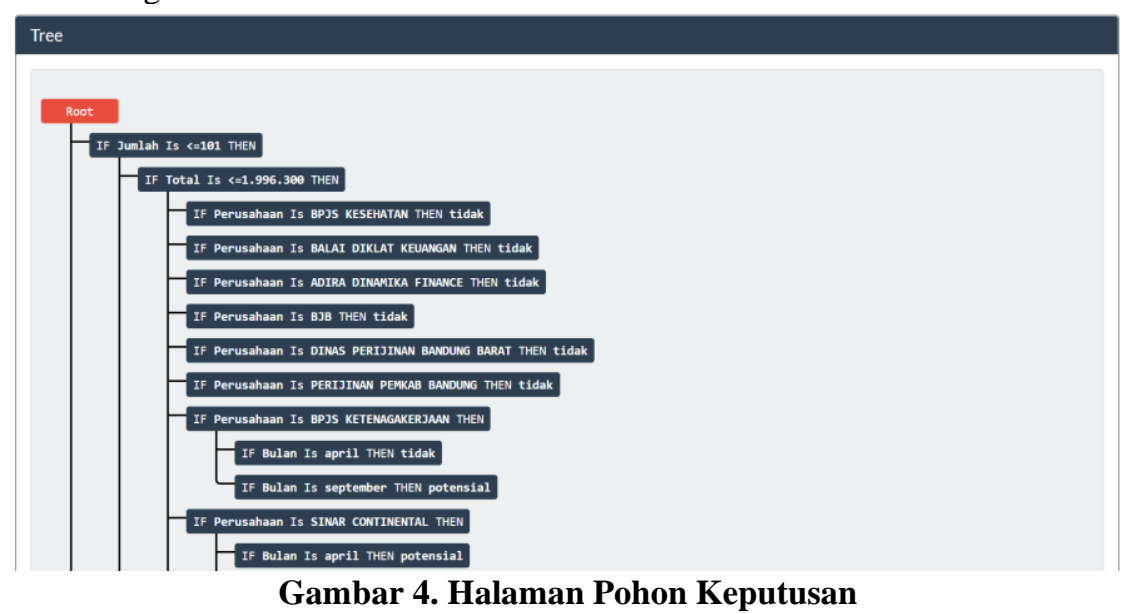

b. Halaman Perhitungan C50 - Testing

Gambar 5 merupakan halaman hasil perhitungan Algoritma C5.0 yang dilakukan oleh sistem. 


\section{Perhitungan Testing}

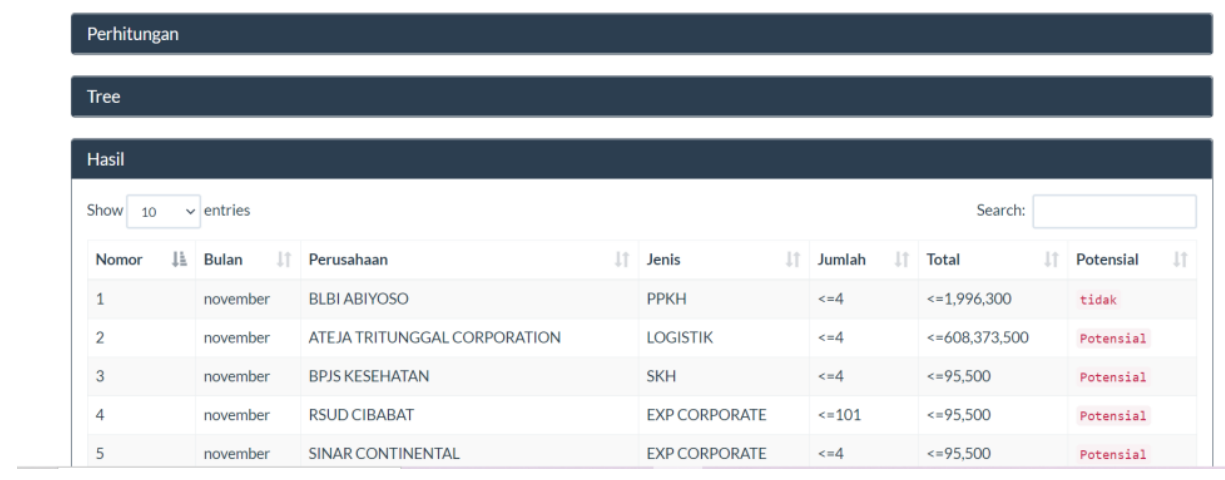

\section{Gambar 5. Hasil Data Testing}

c. Confusion Matrix

Gambar 6 merupakan hasil confusion matrix dari perhitungan Algoritma C 5.0. bisa dilihat dari gambar dibawah ini bahwa akurasi dari perhitungan Algoritma C 5.0. sebesar 96\%.

\begin{tabular}{|llllllll|}
\hline Confusion Matrix & & & & & & & \\
\hline Klasifikasi & TP & FP & TN & FN & Accuracy & Precision & Recall \\
tidak & 194 & 4 & 194 & 12 & 0.96 & 0.98 & 0.942 \\
potensial & 194 & 12 & 194 & 4 & 0.96 & 0.942 & 0.98 \\
\hline
\end{tabular}

Gambar 6. Hasil Confusion Matrix

\section{KESIMPULAN}

Kesimpulan yang dapat diambil Implementasi Algoritma C 5.0 untuk menentukan Pelanggan Potensial di Kantor Pos Cimahi yaitu :

1) Sistem yang telah dibangun dapat membantu bagian penjualan di Kantor Pos Cimahi untuk menentukan pelanggan korporat yang potensial dan tidak sehingga pelanggan yang telah ditentukan sebagai pelanggan potensial dapat diperlakukan secara khusus agar pelanggan tersebut tetap menggunakan jasa dari Kantor Pos Cimahi.

2) Hasil akurasi yang diperoleh dari data transaksi periode bulan januari - oktober 2020 yaitu sebesar $96 \%$.

\section{DAFTAR PUSTAKA}

[1] K. Baindra, "BAGIAN SENTRAL LAYANAN PELANGGAN KORPORAT ( SLPK ) PADA PT POS INDONESIA ( PERSERO ) SURAKARTA Disusun Oleh : Khery Baindra S PROGRAM STUDI DIII MANAJEMEN PEMASARAN," 2014.

[2] A. Khandare and A. S. Alvi, "Efficient Clustering Algorithm with Improved Clusters Quality," Iosr-Jce, vol. 18, no. 6, pp. 15-19, 2016.

[3] Y. S. Nugroho, "Klasifikasi dan Klastering Penjurusan Siswa SMA Negeri 3 Boyolali," Khazanah Inform. J. Ilmu Komput. dan Inform., vol. 1, no. 1, p. 1, 2015.

[4] M. A. Ghofar and Y. I. Kurniawan, "APLIKASI PENGELOMPOKAN PELANGGAN PADA UMS STORE MENGGUNAKAN ALGORITMA K-MEANS, Program Studi Informatika, Fakultas Komunikasi dan Informatika," vol. 4, no. 1, 2018.

[5] Y. Yusuf, "Perbandingan Performansi Algoritma Decision Tree C5 . 0 , Cart ," Seminar, vol. 2007 , no. Snati, pp. 0-3, 2007.

[6] P. W. Kastawan, D. M. Wiharta, and M. Sudarma, "Implementasi Algoritma C5.0 pada Penilaian Kinerja Pegawai Negeri Sipil," Maj. Ilm. Teknol. Elektro, vol. 17, no. 3, p. 371, 2018.

[7] D. Ayu Wahyuning Dewi and I. Cholissodin, "Klasifikasi Penyimpangan Tumbuh Kembang Anak Menggunakan Algoritme C5.0,” vol. 3, no. 10, pp. 10258-10265, 2019.

[8] S. Moedjiono, Y. R. Isak, and A. Kusdaryono, "Customer loyalty prediction in multimedia Service Provider Company with K-Means segmentation and C4.5 algorithm," 2016 Int. Conf. Informatics Comput. ICIC 2016, no. Icic, pp. 210-215, 2017.

[9] R. Pratiwi, M. N. Hayati, and S. Prangga, "Perbandingan Klasifikasi Algoritma C5.0 Dengan Classification and Regression Tree (Studi Kasus : Data Sosial Kepala Keluarga Masyarakat Desa Teluk Baru Kecamatan Muara Ancalong Tahun 2019)," BAREKENG J. Ilmu Mat. dan Terap., vol. 14, no. 2, pp. 273-284, 2020. 